\title{
Fractional-Order PID Controller for Active Power Filter Using Active Disturbance Rejection Control
}

\author{
Nixuan Liu, ${ }^{1}$ Siqi Cao, ${ }^{2}$ and Juntao Fei $\mathbb{D}^{1,3}$ \\ ${ }^{1}$ College of IoT Engineering, Hohai University, Changzhou 213022, China \\ ${ }^{2}$ College of Electrical and Information Engineering, Lanzhou University of Technology, Lanzhou 730050, China \\ ${ }^{3}$ Jiangsu Key Lab of Power Transmission and Distribution Equipment Technology, China \\ Correspondence should be addressed to Juntao Fei; jtfei@yahoo.com
}

Received 25 April 2019; Revised 6 June 2019; Accepted 18 June 2019; Published 1 July 2019

Academic Editor: Filippo Cacace

Copyright (C) 2019 Nixuan Liu et al. This is an open access article distributed under the Creative Commons Attribution License, which permits unrestricted use, distribution, and reproduction in any medium, provided the original work is properly cited.

\begin{abstract}
This paper proposed a fractional-order PID controller and active disturbance rejection control (ADRC) method for the current compensation of active power filter (APF). The control method consists of two closed loops. One is a reference current tracking loop based on the ADRC controller, which can treat the internal and external uncertainties of the system as a whole. The other is the voltage control loop with the fractional-order PID controller for more flexibility. Simulation results demonstrate that the proposed control method has a stronger robustness and higher compensating precision comparing with the double-loop PID control method.
\end{abstract}

\section{Introduction}

It is generally acknowledged that using APF is an effective way to deal with the grid harmonic and reactive power in order to improve the grid quality. However, the research for APF has not been mature, yet there are still lots of problems to be studied and solved. To improve the capacity of APF, recently it has become a trend in the study of the control system, including optimizing the advanced algorithms on current compensating control and DC side voltage tracking control.

The beginning of the research works of APF control system is at the point that the concept of "active power filter" was proposed in the 70th last century, when the "instantaneous reactive power theory" was posed by Akagi et al. [1] Researchers have done much work on the advanced control algorithms to improve the current compensation and voltage tracking respectively [2-7]. Hou et al. [8] combined adaptive fuzzy control with neural network control on the active power filter to eliminate harmonics. Fei et al. [9] used an adaptive sliding mode controller to combine neural network control in order to eliminate harmonics. Zhu et al. [10] adopted fuzzy sliding mode control on PV Grid Connected Inverter creatively to ensure the good robustness of the system.
The Active Disturbance Rejection Control (ADRC) algorithm firstly was proposed by Han et al. [11-13] and Sun [14]. It consists of Tracking Differentiator (TD), Extended State Observer (ESO), and Nonlinear Error State Feedback law (NLSEF). This control method inherits good qualities from PID [13]. It is a nonlinear control structure based on the process error instead of the plant model. This feature brings the ADRC to wider fields of the engineering application than the traditional PID control method. Xia et al. [15] presented a tracking control method for the lateral motion of an autonomous land vehicle based on ADRC scheme and differential flatness theory. Zhu et al. [16] designed an airship horizontal trajectory tracking control based on ADRC. ADRC method has been discussed for hypersonic reentry vehicle and uncertain nonlinear systems $[17,18]$.

Meanwhile, the fractional-order calculus is also mentioned in this paper. Within the last decades, fractional-order calculus has been used in many scientific fields, especially in control engineering. It is a branch of mathematics in which the integer order of the conventional differential equation is extended to a noninteger (fractional) number. Li et al. [19] verified that a fractional-order proportional and derivative controller is suitable for the closed-loop system that can enhance the system robustness. Tseng et al. [20] designed a 


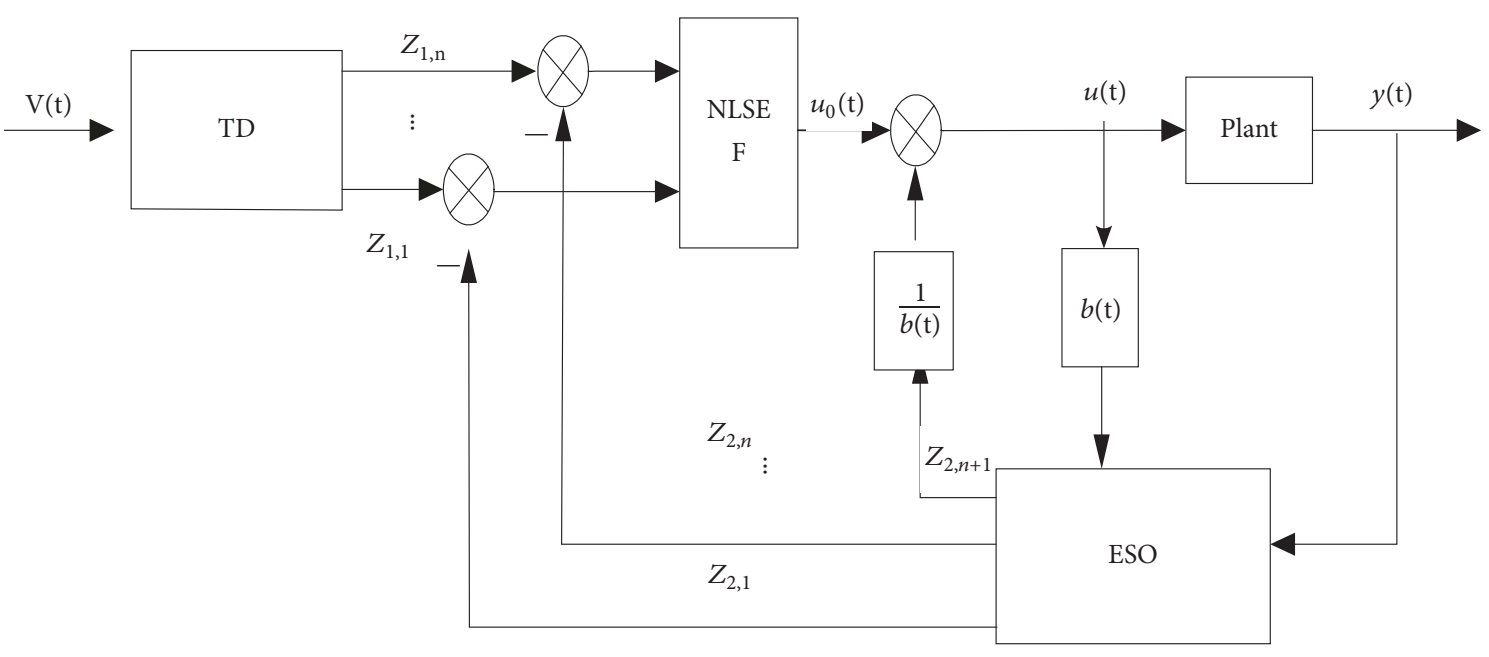

FIGURE 1: Structure diagram of ADRC.

fractional-order FIR differentiators. Doye et al. [21] proposed a state observer design for constructing a chaotically synchronized systems and fractional-order direct Lyapunov theorem is used to ensure the closed-loop asymptotic stability. Adaptive fuzzy-neural fractional-order controller using a finitetime sliding mode method was developed in [22-27].

As a result, the ADRC and fractional-order PID compound controller are combined together to be applied in the APF to make use of both advantages of the two algorithms, which include the strong robust and fast response of ADRC and flexibility of fractional-order PID. The stability of the ADRC was investigated in [28]. The contributions of the work compared with existing works can be concluded as follows.

(1) It is firstly proposed that the combined algorithm of ADRC and fractional-order PID is applied for the current compensation and voltage tracking on APF. ADRC is such a control method that considers the uncertainties as a whole, which means the working principle of APF can be simpler without harmonic detection module.

(2) The APF control system has two control loops: the reference current tracking loop with $\mathrm{ADRC}$ and the voltage tracking loop with the fractional-order PID controller. The fractional-order PID can improve the flexibility and the robustness of the system.

In this paper, the control theory of ADRC control is discussed in Section 2. The control theory of fractional-order PID control is introduced in Section 3. The control system is then given in Section 4. The simulation study is presented in Section 5. Finally conclusion is given in Section 6.

\section{Active Disturbance Rejection Control (ADRC) Theory}

Normally, an ADRC system contains three parts, including Tracking Differentiator (TD), Extended State Observer (ESO), and Nonlinear State Error Feedback Law (NLSEF). The framework of this controller is shown in Figure 1, where
$Z_{1,1}, \ldots, Z_{1, n}$ are the tracking signals of derivatives of the reference input $\mathrm{V}(t)$ through TD. $Z_{2,1}, \ldots, Z_{2, \mathrm{n}}$ are the state variables of plant estimated in ESO. $Z_{2, \mathrm{n}+1}$ is the real-time function value. By subtracting $z_{1, n}$ and $z_{2, n}$, we can obtain the control law through the process of NLSEF.

2.1. Extended State Observer (ESO). For an uncertain system,

$$
y^{(n)}=f\left(y, \dot{y}, \ldots, y^{(n-1)}, t\right)+\omega(t)+b u
$$

It can be rewritten in another form as

$$
\begin{gathered}
\dot{x}_{1}=x_{2} \\
\vdots \\
x_{n-1}=x_{n} \\
\dot{x}_{n}=f\left(x_{1}, x_{2}, \ldots, x_{n-1}, x_{n}\right)+\omega(t)+b u \\
y=x_{1}
\end{gathered}
$$

where $f\left(x_{1}, x_{2}, \ldots, x_{n-1}, x_{n}\right)+\omega(\mathrm{t})+b u$ is unknown, $\omega(\mathrm{t})$ is an uncertain external disturbance, $b$ is a known parameter. Then we can design an extended state observer (ESO) as

$$
\begin{gathered}
\dot{z}_{2,1}=z_{2,2}-g_{1}\left(z_{2,1}-y(t)\right) \\
\vdots \\
\dot{z}_{2, n}=z_{2, n+1}-g_{n}\left(z_{2,1}-y(t)\right)+b u(t) \\
\dot{z}_{2, n+1}=-g_{n+1}\left(z_{2,1}-y(t)\right)
\end{gathered}
$$

Then we set $\alpha(\mathrm{t})=f\left(x_{1}, x_{2}, \ldots, x_{n-1}, x_{n}\right)+\omega(\mathrm{t}) ; x_{1}, x_{2}$, $\ldots, x_{n-1}, x_{n}, \alpha(\mathrm{t})$ can be seen as extended state variables. 


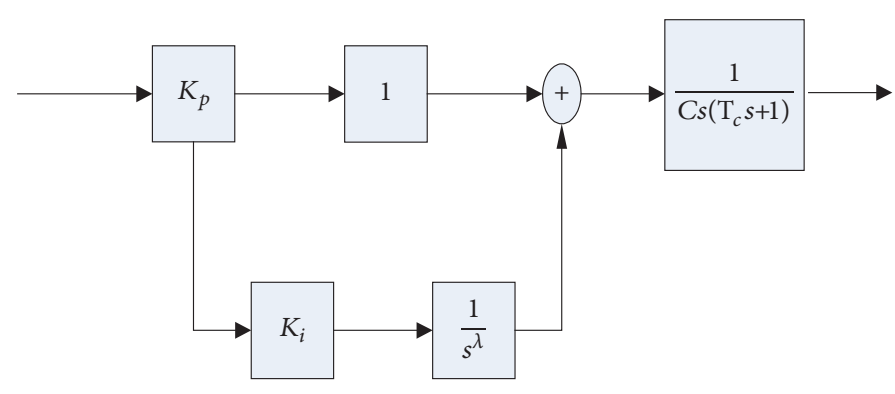

FIGURE 2: Framework of the fractional-order PID.

$z_{2, i} i=1,2, \ldots, n+1$ are the output variables of the observer. Let output variables track extended variables, described as

$$
\begin{aligned}
& z_{2,1}(\mathrm{t}) \longrightarrow \mathrm{x}_{1}(\mathrm{t}), \ldots, \mathrm{z}_{2, n} \longrightarrow x_{n}(\mathrm{t}) \\
& \mathrm{z}_{2, n+1} \longrightarrow \alpha(\mathrm{t})
\end{aligned}
$$

Choose appropriate nonlinear functions $g_{1}(\mathrm{z}), g_{2}(\mathrm{z})$, $\ldots, g_{n}(\mathrm{z}), g_{n+1}(\mathrm{z})$ to achieve the track target. Then, the equation can be written as

$$
z_{2, n+1}=\widehat{\alpha}(\mathrm{t})
$$

In fact, when $f\left(\mathrm{x}, \dot{\mathrm{x}}, \ldots, x^{(\mathrm{n}-1)}, \mathrm{t}\right)$ and $\omega(\mathrm{t})$ are unknown, $z_{2, n+1}=\widehat{\alpha}(\mathrm{t})$ can be seen as the estimated value of $a(\mathrm{t})$. It can compensate the uncertain external disturbance. Thus, ESO is actually such a process; when the system output is calculated in ESO, the derivative signals and the estimated signal of the system disturbance can be obtained for the convenience of the next step.

2.2. Nonlinear State Error Feedback Law (NLSEF). According to the outputs of ESO and TD, the error between them can be obtained as

$$
\varepsilon_{i}=z_{1, \mathrm{i}}-z_{2, i}, \quad(\mathrm{i}=1, \ldots, \mathrm{n})
$$

Then, the nonlinear error feedback of the system can be written as

$$
u_{0}(\mathrm{t})=k_{1} f a l\left(\mathrm{e}_{1}, \alpha, \delta\right)+\cdots+k_{n} f a l\left(\mathrm{e}_{n}, \alpha, \delta\right)
$$

where $k_{i}, \alpha, \delta$ are adjustable parameters.

Generally, $f a l(\mathrm{e}, a, \delta)$ is such a kind of nonlinear functions as

$$
f a l\left(\varepsilon_{i}, \alpha, \delta\right)= \begin{cases}\left|e_{i}\right|^{\alpha} \operatorname{sgn}\left(e_{i}\right), & \left|e_{i}\right|>\delta \\ \frac{e_{i}}{\delta^{1-\alpha}}, & \left|e_{i}\right| \leq \delta\end{cases}
$$

Just as we can see $f a l(\mathrm{e}, a, \delta)$, it is actually a nondifferentiable function. It will avoid the influence of oscillation when the error changes in linear range. While $\delta$ is very small, the saltation of derivate could make the property of system worse and create larger saltation. So due to the fact that the control performance is sensitive to $\delta$, a continuous and smooth nonlinear function is more suitable for this control system, as follows:

$$
\begin{aligned}
& \operatorname{qin}(\mathrm{e}, a, \delta) \\
& = \begin{cases}(a-1) \delta^{a-3} e^{3}-(a-1) \delta^{a-2} e^{2} \operatorname{sign}(e)+\delta^{a-1} e, & |e| \leq \delta \\
|e|^{a} \operatorname{sign}(e), & |e|>\delta\end{cases}
\end{aligned}
$$

Then, we can get the system control law as

$$
u(t)=u_{0}(t)-\frac{\widehat{\alpha}(t)}{b}
$$

\section{Fractional-Order PID Control}

The transfer function of fractional-order $\mathrm{PI}^{\lambda} \mathrm{D}^{\mu}$ controller is

$$
G_{f_{o}}(\mathrm{~s})=\mathrm{K}_{P}+\frac{K_{i}}{s^{\lambda}}+K_{d} s^{\mu}
$$

where $\lambda$ denotes integral order and $\mu$ denotes differential order. According to the performance index of the control system, we can optimize the parameters of the controller, such as $K_{p}, K_{i}, K_{d}, \lambda, \mu$.

In this paper, we choose a fractional-order $P I^{\lambda}$ as system controller whose transfer function can be written as

$$
G_{f o}(s)=K_{P}\left(1+\frac{K_{i}}{s^{\lambda}}\right)
$$

The framework of the fractional-order $P I^{\lambda}$ can be shown in Figure 2. This controller is based on Flat phase theory proposed by Chen [29] and the index of amplitude margin and phase margin can be obtained as

$$
\begin{aligned}
& \arg \left(G_{k}(j \omega)\right)=\arg \left(G_{f o}(j \omega) G_{s}(j \omega)\right)=-\pi+\varphi_{m} \\
& \left(\frac{d\left(\arg \left(G_{f o}(j \omega) G_{s}(j \omega)\right)\right)}{d \omega}\right)_{\omega=\omega_{c}}=0 \\
& \left\{\left|G_{k}\left(j \omega_{c}\right)\right|\right\}_{d B}=\left\{\left|G_{s}\left(j \omega_{c}\right) G_{f o}\left(j \omega_{c}\right)\right|\right\}_{d B}=0
\end{aligned}
$$

where $\omega_{c}$ and $G_{k}(j \omega)$ denote the cut-off frequency open-loop transfer function respectively. 


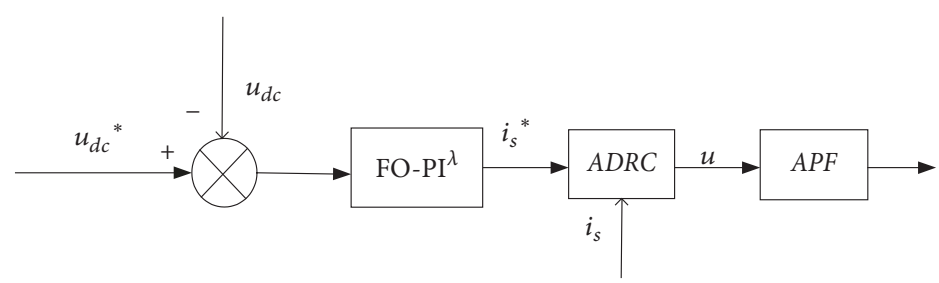

FIGURE 3: Framework of the control system.

According to (11), the frequency response of the controller can be obtained as

$$
\begin{aligned}
& G_{f_{o}}(j \omega) \\
& \quad=K_{p}\left[\left(1+K_{i} \omega^{-\lambda} \cos \frac{\lambda \pi}{2}\right)-j K_{i} \omega^{-\lambda} \sin \frac{\lambda \pi}{2}\right]
\end{aligned}
$$

The phase and amplitude of the controller can be also obtained as

$$
\begin{aligned}
& \arg \left(G_{f o}(j \omega)\right) \\
& =\arctan \left(\frac{K_{i} \omega^{-\lambda} \sin (\lambda \pi / 2)}{1+K_{i} \omega^{-\lambda} \cos (\lambda \pi / 2)}\right)\left|G_{f o}(j \omega)\right| \\
& =K_{p} \sqrt{\left(K_{i} \omega^{-\lambda} \sin (\lambda \pi / 2)\right)^{2}+\left(1+K_{i} \omega^{-\lambda} \cos (\lambda \pi / 2)\right)^{2}}
\end{aligned}
$$

The transfer function of the controlled device can be written as

$$
G_{s}(s)=u_{d c r} \frac{1}{T_{c} s+1} \cdot \frac{1}{C u_{d c r} s}=\frac{1}{C s\left(T_{c} s+1\right)}
$$

So the frequency response of the controlled device can be calculated as

$$
G_{s}(j \omega)=\frac{1}{j \omega T_{c}+1} \cdot \frac{1}{j \omega C}=\frac{1}{-T_{c} C \omega^{2}+j \omega C}
$$

The phase and amplitude can be also obtained as

$$
\begin{aligned}
\arg \left(\mathrm{G}_{f o}(j \omega)\right) & =-\arctan \left(\omega T_{c}\right)-\frac{\pi}{2}\left|\mathrm{G}_{f o}(j \omega)\right| \\
& =\frac{1}{\omega C \sqrt{1+\left(\omega T_{c}\right)^{2}}}
\end{aligned}
$$

The open-loop transfer function of the system is written as

$$
G_{k}(s)=G_{f o}(s) G_{s}(s)
$$

The frequency response, the phase, and amplitude of the system are deduced as

$$
\begin{aligned}
& \arg \left(G_{k}(j \omega)\right)=\arg \left(G_{f o}(j \omega) G_{s}(j \omega)\right) \\
& =\arg \left(G_{f o}(j \omega)\right)+\arg \left(G_{s}(j \omega)\right) \\
& =-\arctan \left(\frac{K_{i} \omega^{-\lambda} \sin (\lambda \pi / 2)}{1+K_{i} \omega^{-\lambda} \cos (\lambda \pi / 2)}\right)-\arctan \left(\omega T_{c}\right) \\
& \quad-\frac{\pi}{2} \\
& \left\{\left|G_{k}\left(j \omega_{c}\right)\right|\right\}_{d B}=\left|G_{s}\left(j \omega_{c}\right) G_{f o}\left(j \omega_{c}\right)\right|_{d B} \\
& =\frac{K_{p} \sqrt{\left(K_{i} \omega^{-\lambda} \sin (\lambda \pi / 2)\right)^{2}+\left(1+K_{i} \omega^{-\lambda} \cos (\lambda \pi / 2)\right)^{2}}}{\omega C \sqrt{1+\left(\omega T_{c}\right)^{2}}}
\end{aligned}
$$

According to (13)-(15), it can be deduced as

$$
\begin{aligned}
& K_{p} \\
& =\frac{\omega C \sqrt{1+\left(\omega T_{c}\right)^{2}}}{\sqrt{\left(K_{i} \omega^{-\lambda} \sin (\lambda \pi / 2)\right)^{2}+\left(1+K_{i} \omega^{-\lambda} \cos (\lambda \pi / 2)\right)^{2}}} \\
& K_{i}=\frac{-F \pm \sqrt{F^{2}-4 E^{2} \omega^{2 \lambda}}}{2 E}
\end{aligned}
$$

where $F=2 E \omega^{\lambda} \cos (\lambda \pi / 2)-\lambda \omega^{\lambda-1} \sin (\lambda \pi / 2), E=$ $T_{c} /\left(\left(T_{c} \omega\right)^{2}+1\right), 1 /\left(T_{c} s+1\right)$ is a low pass filter of system.

\section{Active Power Filter Control}

This proposed APF working principle contains two loops; one is the internal loop of the reference current tracking and the other is the external loop of voltage control for DC side. The internal loop is to compensate the harmonic current by the switches in the main circuit. The PWM can control the conditions of those switches (ON/OFF) when the ADRC gives the modulation signals. The external loop can get the reference current by the fractional-order PID control and import to the internal loop. The framework of the control system is plotted in Figure 3. For the consideration of the feature that the fractional-order PID control is not sensitive to the parameter variance and has strong robust, it is applied for the voltage control. 


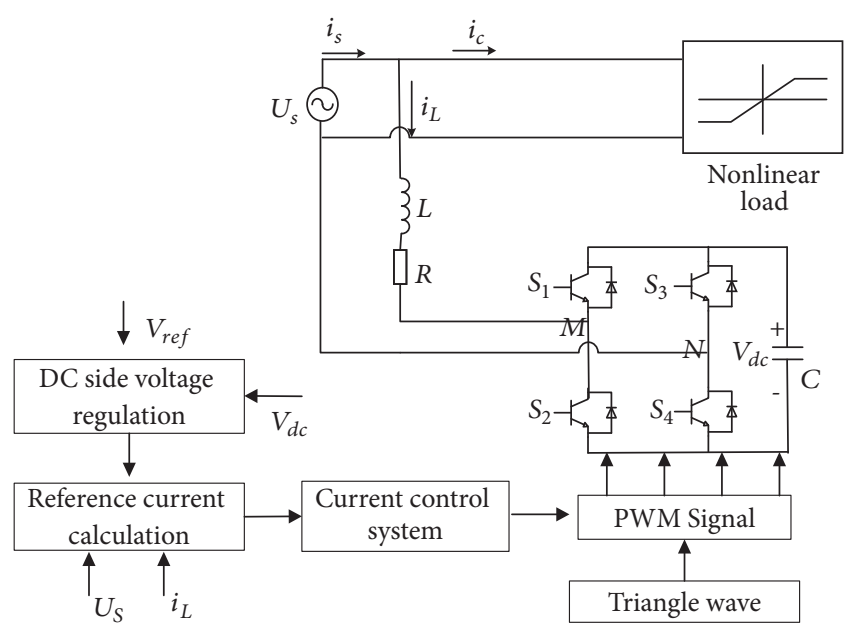

FIGURE 4: Single-phase active power filter structure.

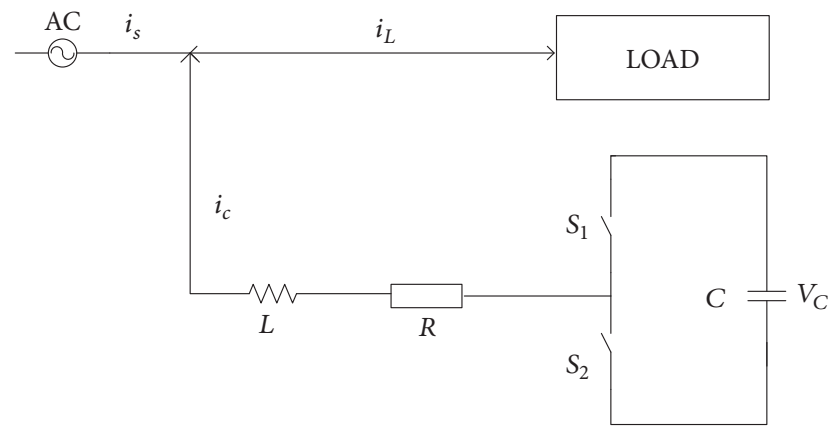

Figure 5: The diagram of the main circuit.

4.1. The Current Control with an ADRC Controller. The basic circuit structure of a single-phase active power filter is shown in Figure 4 , where $v_{s}$ is a grid voltage, $i_{s}$ is a grid current, $i_{c}$ is a filter output compensation current, $L$ is an AC inductor, $R$ is an equivalent resistor, and $C$ is a DC capacitor.

APF consists of three parts, including the harmonic current detection module, the current tracking control module, and the compensation current module. However, when the proposed ADRC control method is applied, the harmonic current module can be not necessary any more.

The APF model is shunt single-phase one and the main circuit can be equivalent to the diagram as shown in Figure 5.

According to the circuit theory and Kirchhoff's voltage law, the mathematic model can be written as

$$
L \frac{d i_{s i}}{d t}=-R i_{s i}-b u+\omega(t) \quad i=a, b, c
$$

where $\omega(t)=u_{s}+R i_{L}+L\left(d i_{L} / d t\right), u$, as switch function is the control value of the system.

Set the first-order output of TD:

$$
\dot{z}_{1,1}=-k_{0} f a l\left(\mathrm{z}_{11}-\operatorname{ref}, \alpha_{0}, \delta_{0}\right)
$$

where $k_{0}, \alpha_{0}, \delta_{0}$ are the parameters to be selected; we can design the ESO as

$$
\begin{aligned}
& \dot{z}_{2,1}=z_{2,2}-k_{11} f a l\left(\mathrm{e}, \alpha_{1}, \delta_{1}\right)+b u(t) \\
& \dot{z}_{2,2}=-k_{12} f a l\left(\mathrm{e}, \alpha_{1}, \delta_{1}\right)
\end{aligned}
$$

where $\varepsilon=z_{2,1}-i_{c}, k_{11}, k_{12}, \alpha_{1}, \delta_{1}$ are the parameters to be selected. Though $\varepsilon=z_{1,1}-z_{2,1}$, as the feedback signal of the system state error, we can get the ADRC law as

$$
\begin{aligned}
u_{0} & =k_{2} f a l\left(e_{1}, \alpha, \delta\right) \\
u & =u_{0}-\frac{z_{2,2}}{b}
\end{aligned}
$$

where $k_{2}, \alpha, \delta$ are also the parameters to be selected. From (29), we could find out that the control law has nothing to do with the model uncertainties and external disturbances, only related to the given input and the system output.

4.2. The Voltage Control with a Fractional-Order PID Controller. When the reference voltage on the DC side $u_{d c r}=$ $700 \mathrm{~V}, \varphi_{m}=60^{\circ}, \omega_{c}=10 \mathrm{rad} / \mathrm{s}$, it can be derived that $K_{i}=88.3, \lambda=1.2, K_{P}=0.68$ and the transfer function of the controller can be written as

$$
G_{f o}(s)=0.68\left(1+\frac{88.3}{s^{1.2}}\right)
$$

where $1 / s^{1.2}$ is substituted by Oustaloup Filter [30]. The original fractional-order transfer function can be approached by the integral-order one. As a result, the high order term $s^{-1.2}$ can be approximated by $s^{-1} s^{-0.2}$. It can be written as

$$
\begin{aligned}
& \frac{1}{s^{1.2}} \\
& \quad=\frac{79.4328(s+0.05623)(s+1)(s+17.78)}{s(s+0.03162)(s+0.5623)(s+10)(s+177.8)}
\end{aligned}
$$

\section{Simulation Study}

In order to verify the feasibility of the proposed control strategy, the simulation has been done in the MATLAB/ Simulink with the APF model (24). The supply voltage $V_{s}=$ $380 \mathrm{~V}, f=50 \mathrm{~Hz}$. The nonlinear load is applied in the system, where $R=100 \Omega, L=2 m H$. When $\mathrm{t}=0.1$ s, another same nonlinear load is added in the system in order to test the proposed controller. According to (24) and (25), $K_{p}=0.68$, $K_{i}=88.3, \lambda=1.2$.

We can see the control effects obviously from two kinds of figures; some are without APF control and the others are with ADRC and fractional-order PID control method. The simulation results can be seen in the Figures 6-14.

Figure 6 shows the grid current waveform in APF without any control methods. It can be seen that due to the presence of nonlinear load, the grid current waveform has severe distortion that will affect the quality of grid power. As can be seen from the waveform in Figure 7 compared with Figure 6, the grid current distortion has been significantly improved when the proposed controller is used in the system. 


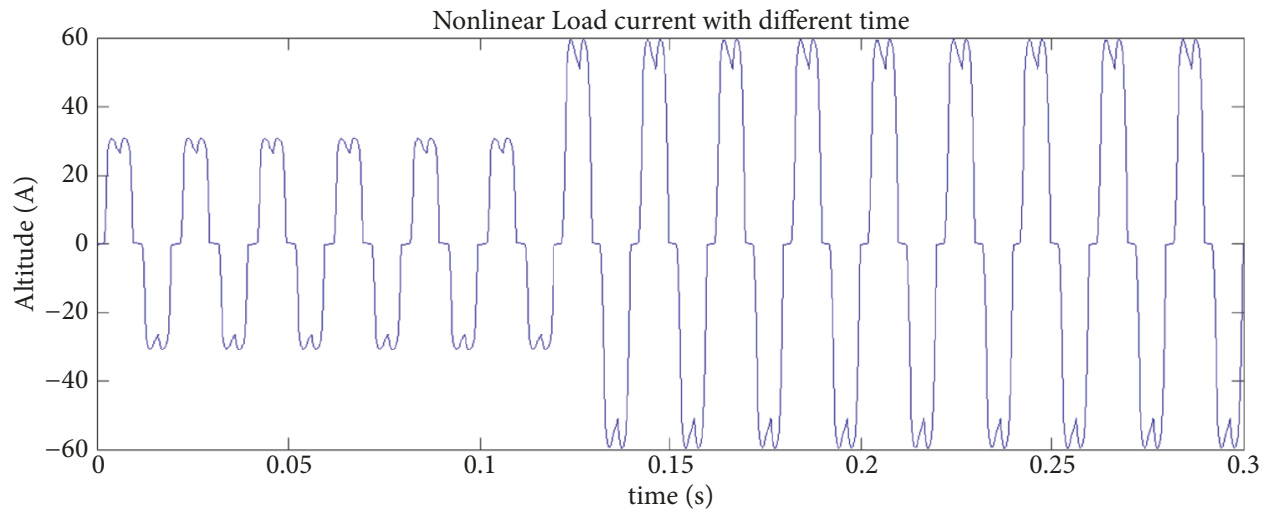

Figure 6: Load current waveform when the nonlinear load changes in 0 0.3s.

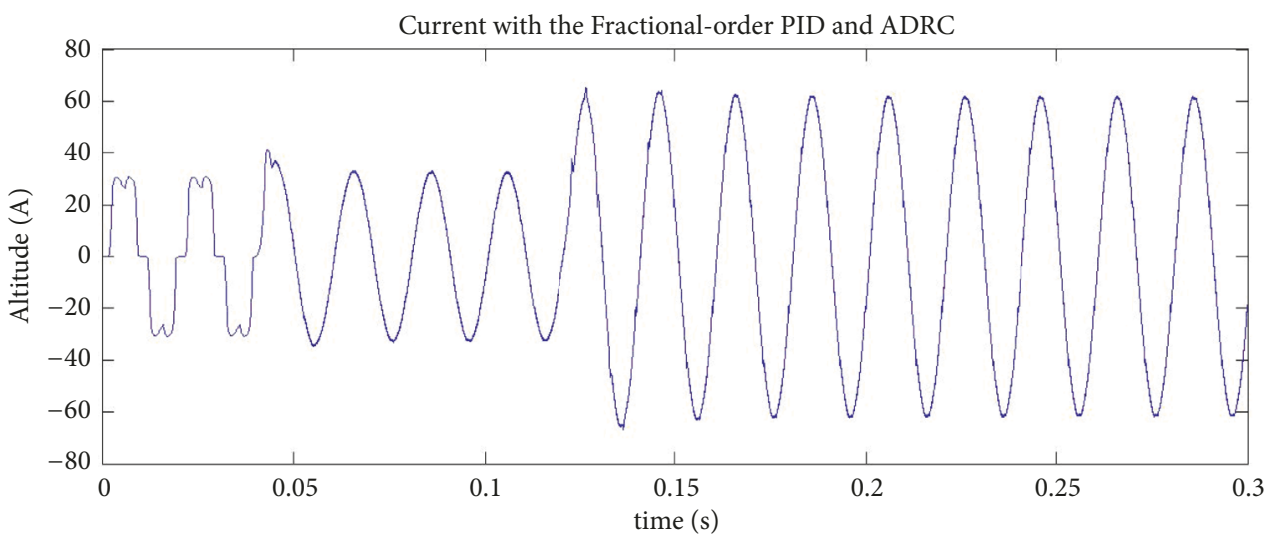

FIGURE 7: Grid current waveform with the proposed controller.

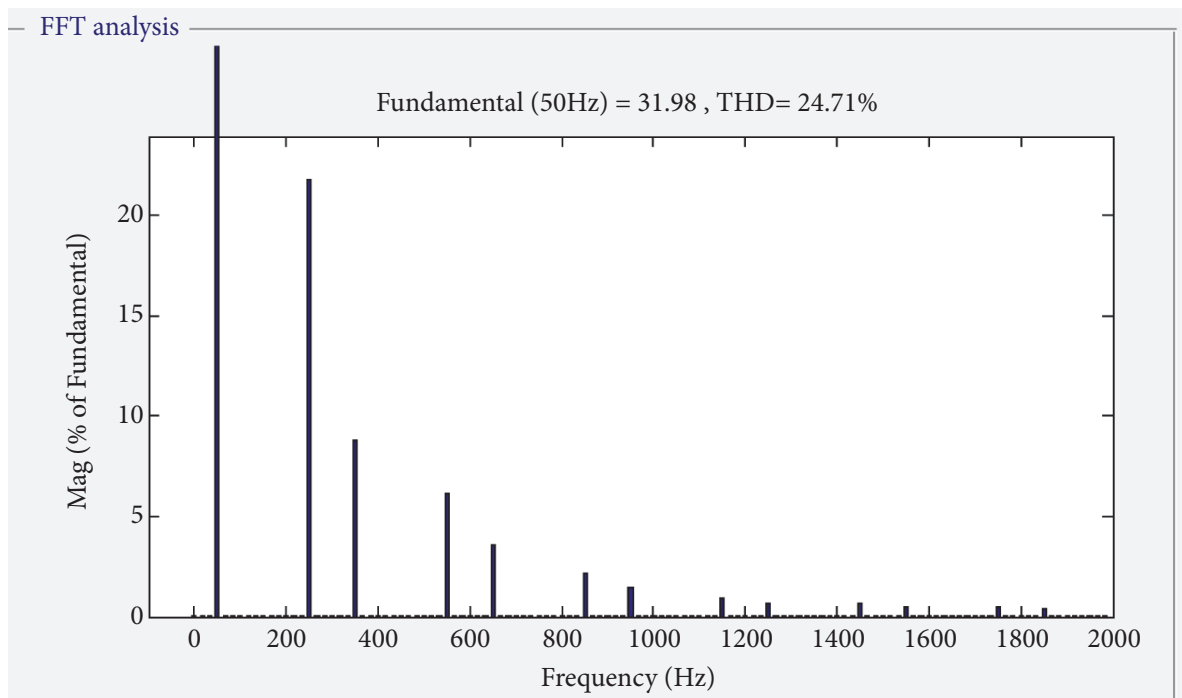

FIGURE 8: Initial grid current spectrogram without controller. 


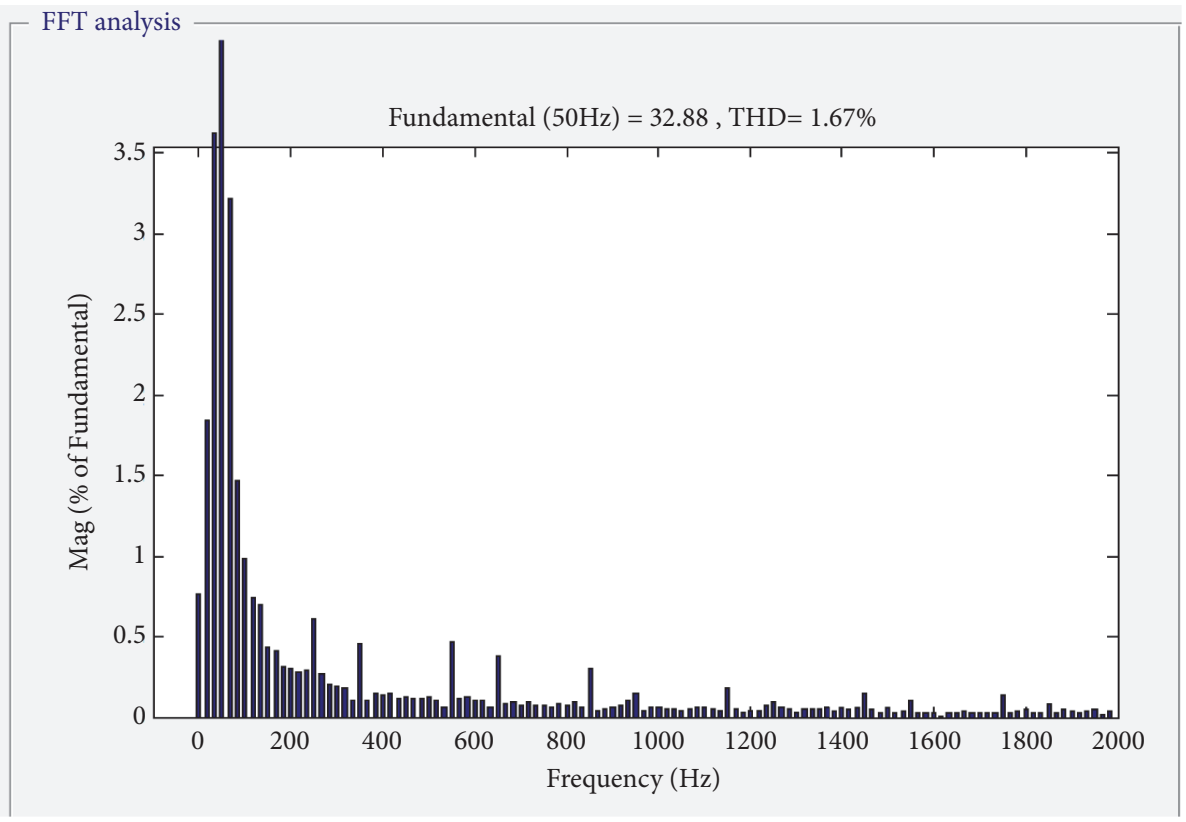

FIGURE 9: Grid current spectrogram with the proposed controller in $0.05 \mathrm{~s}$.

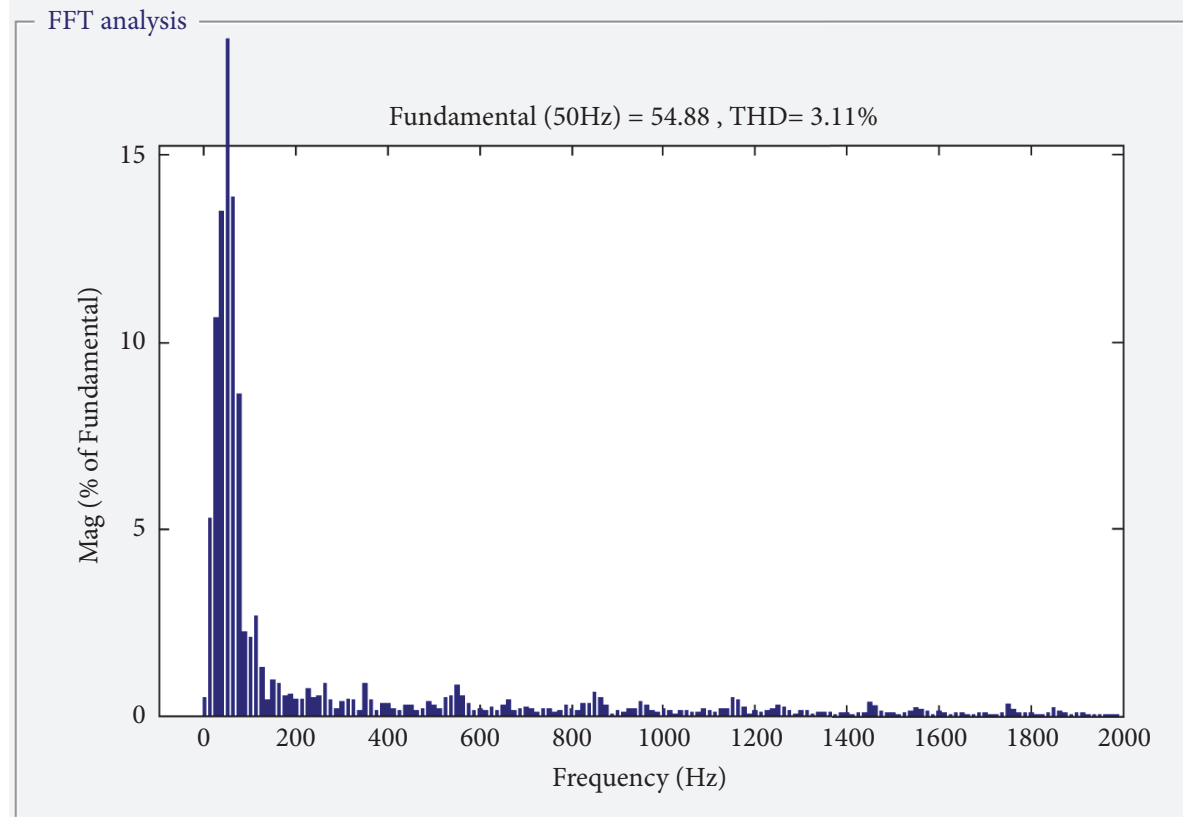

FIGURE 10: Grid current spectrogram with the proposed controller in 0.1s.

Figure 8 shows that nonlinear load leads grid current containing a large number of harmonics. Figures 9-11 plot the harmonic content with ADRC control based on fractionalorder PID control. It is shown that the ADRC and fractionalorder PID control are effective in harmonic suppression of APF.

As a consequence, from Figures 6-11, it is obvious that with the nonlinear load impact increasing asymptotically, ADRC and fractional-order PID for current control of an
APF illustrate good tracking performance, suitability, and robustness at different simulation stage.

Here, in order to demonstrate the advantage of the proposed controller more clearly, a comparative control method that consists of double-loop PID for current control on the AD side and PID for voltage control on the DC side is proposed. It can be seen in Table 1, which compared the double-loop PID control and the fractional-order PID and ADRC control method in their THD in different loads. 
TABLE 1: THD values with different methods.

\begin{tabular}{lccrr}
\hline & \multirow{2}{*}{ THD Values } & \multicolumn{3}{c}{ Different Simulation Time } \\
& & Without APF & $0.05 \mathrm{~s}$ & $0.1 \mathrm{~s}$ \\
\hline \multirow{2}{*}{ Different Methods } & Fractional-order PID and ADRC & $24.71 \%$ & $1.67 \%$ & $2.62 \%$ \\
& Double-loop PID & $24.71 \%$ & $1.98 \%$ & $4.18 \%$ \\
\hline
\end{tabular}

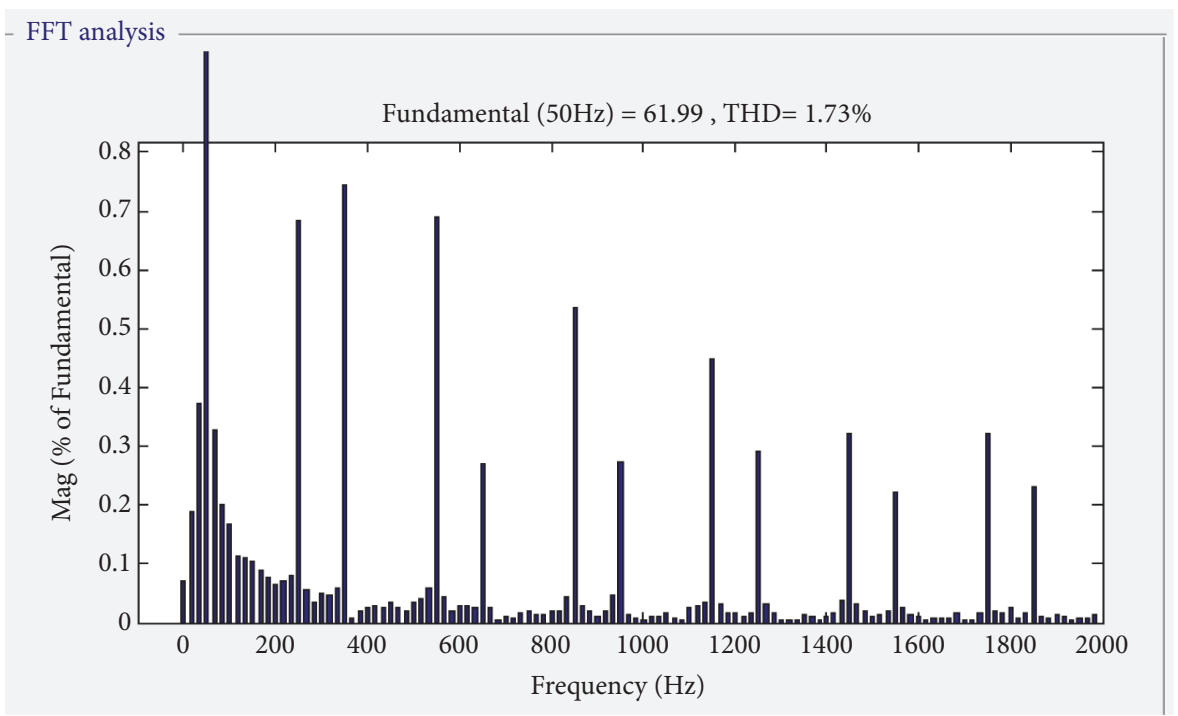

FIGURE 11: Grid current spectrogram with the proposed controller in $0.15 \mathrm{~s}$.

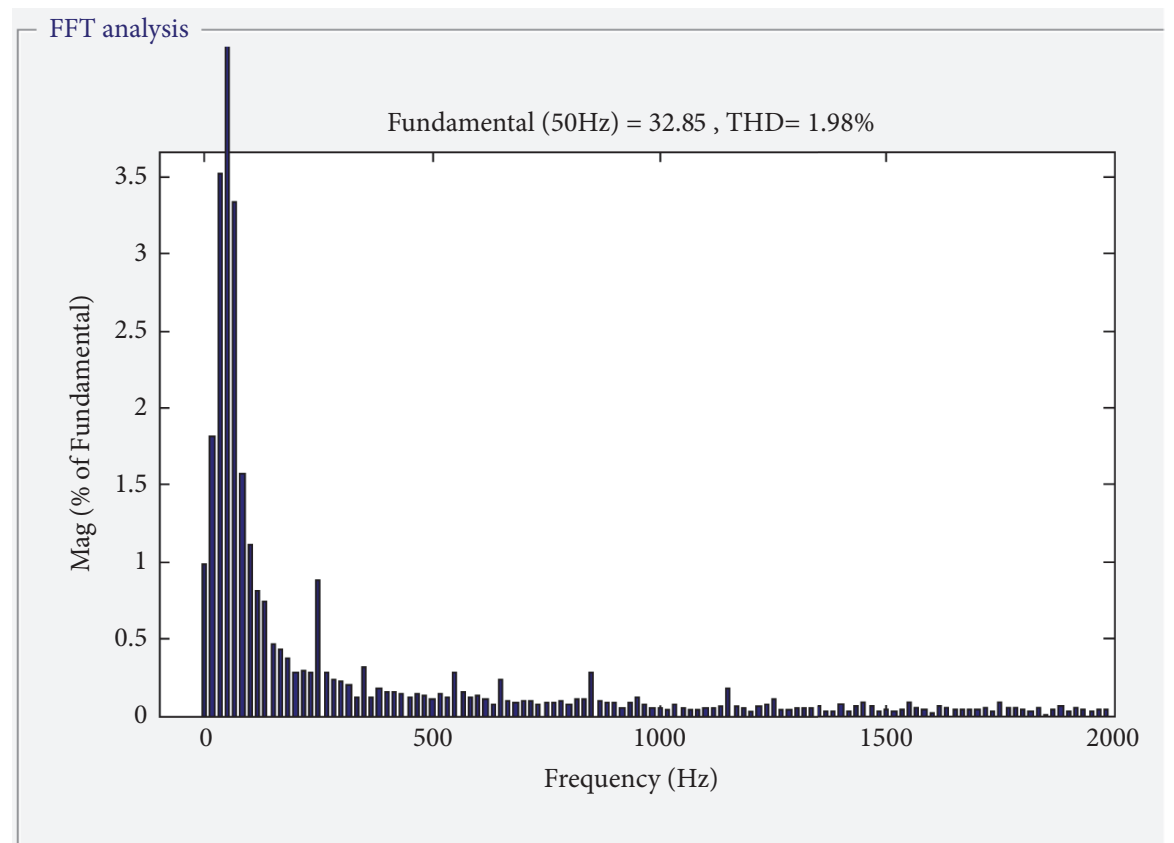

FIGURE 12: 0.05s Grid current spectrogram with double-loop PID controller.

From Figures 9-14 and Table 1, it is obvious that with the nonlinear load impact increasing asymptotically, fractionalorder PID and ADRC for current control of an APF illustrate better tracking performance, suitability and robustness at different simulation stage than the one based on double-loop PID.

\section{Conclusion}

In this paper, a compound control method consisting of ADRC and fractional-order PID is used in shunt APFsuccessfully. According to the established mathematical model of APF, the referenced current can be obtained by 


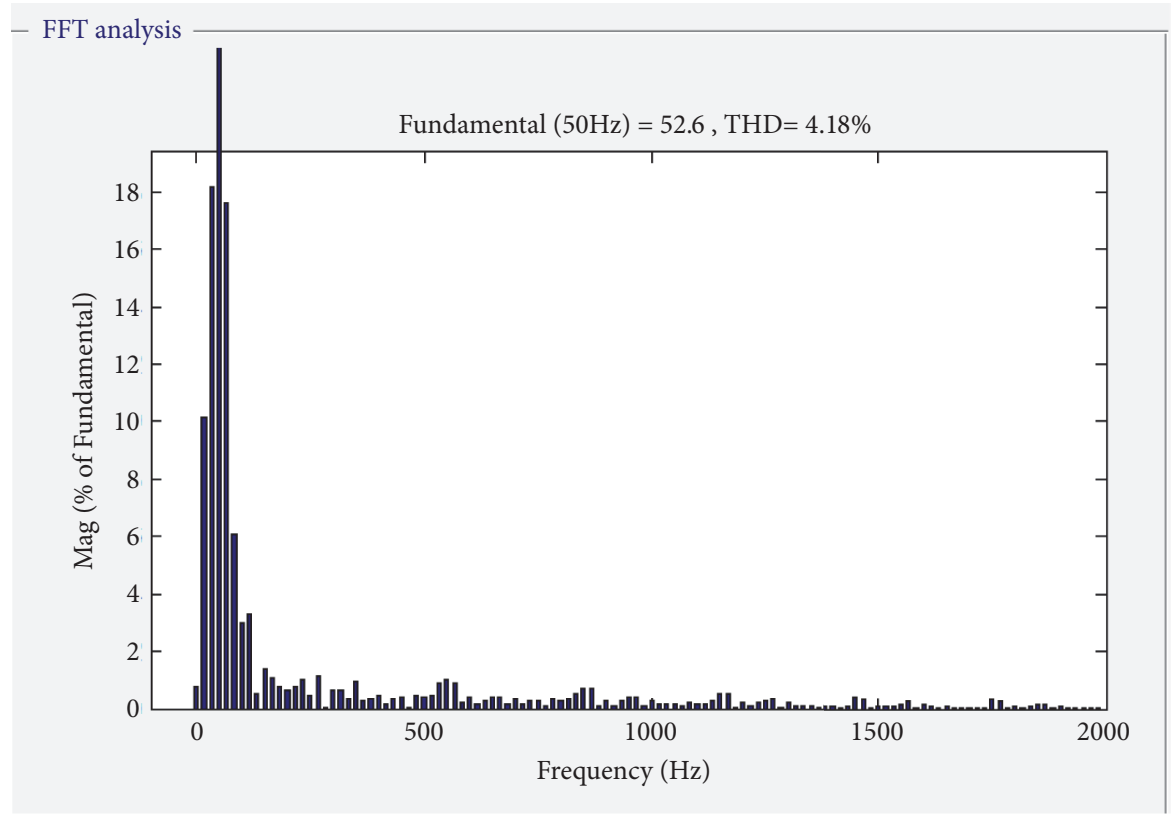

FIgURE 13: 0.1s Grid current spectrogram with the double-loop PID controller.

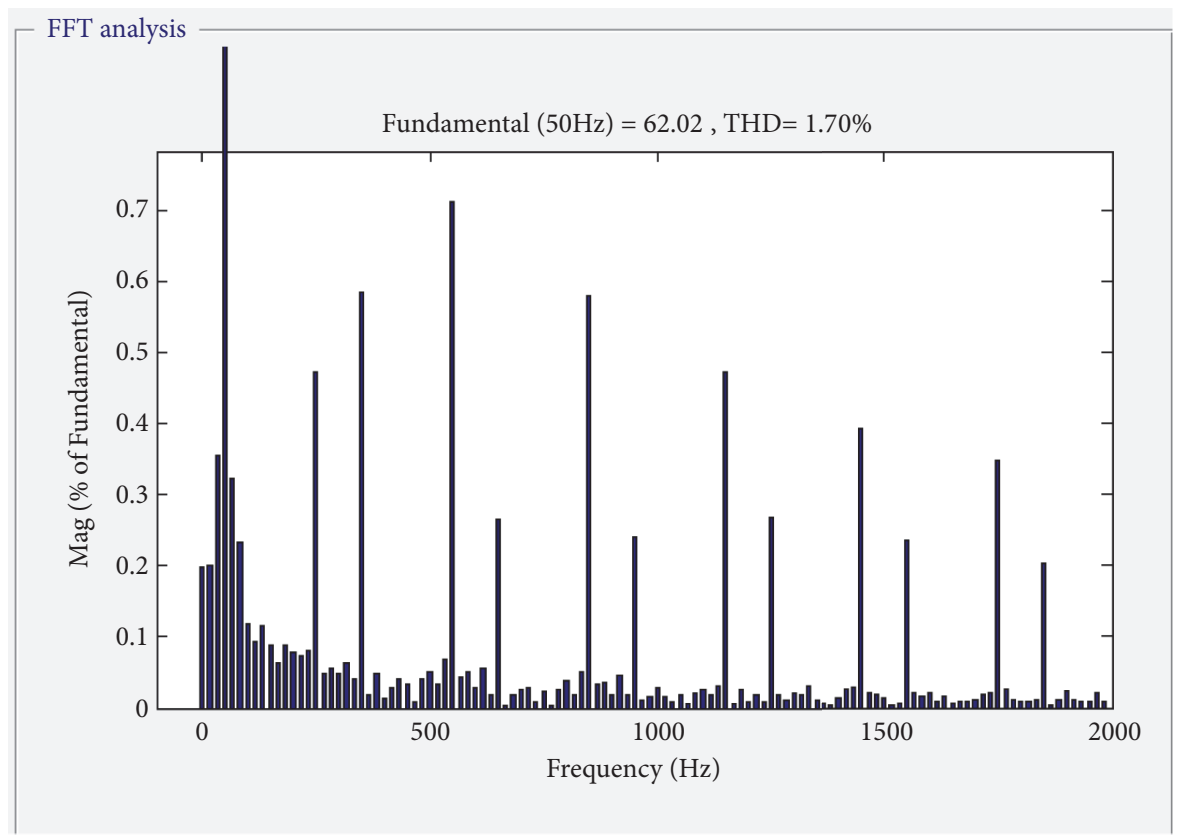

FIGURE 14: 0.15s Grid current spectrogram with the double-loop PID controller.

fractional-order PID method applied to the voltage control module on DC side, then the control law can be derived by the ADRC method applied to the current compensation module, which can be seen as the PWM signal to control the main circuit to gain the compensation current. Simulation results verified that the presented method has a stronger robustness and higher compensation accuracy, compared to the doubleloop PID method.

\section{Data Availability}

The data used to support the findings of this study are included within the article.

\section{Conflicts of Interest}

The authors declare that there are no conflicts of interest regarding the publication of this paper. 


\section{Acknowledgments}

The abstract of this paper was presented in 2017 29th Chinese Control and Decision Conference (CCDC). This work is supported by National Science Foundation of China under Grant No. 61873085, Natural Science Foundation of Jiangsu Province under Grant No. BK20171198, and the Fundamental Research Funds for the Central Universities under Grant No. 2017B 20014.

\section{References}

[1] H. Akagi, Y. Kanazawa, and A. Nabae, "Instantaneous reactive power compensators comprising switching dectives without energy storage components," IEEE Transactions on Industry Applications, vol. 20, no. 3, pp. 625-630, 1984.

[2] M. Angulo, D. A. Ruiz-Caballero, J. Lago, M. L. Heldwein, and S. A. Mussa, "Active power filter control strategy with implicit closed-loop current control and resonant controller," IEEE Transactions on Industrial Electronics, vol. 60, no. 7, pp. 27212730, 2013.

[3] F. Briz, P. Garcia, M. W. Degner, D. Diaz-Reigosa, and J. M. Guerrero, "Dynamic behavior of current controllers for selective harmonic compensation in three-phase active power filters," IEEE Transactions on Industry Applications, vol. 49, no. 3, pp. 1411-1420, 2013.

[4] A. Fereidouni, M. A. S. Masoum, and K. M. Smedley, "Supervisory nearly constant frequency hysteresis current control for active power filter applications in stationary reference frame," IEEE Power and Energy Technology Systems Journal, vol. 3, no. 1, pp. 1-12, 2016.

[5] A. Ribeiro, "A robust DC-link voltage control strategy to enhance the performance of shunt active power filters without harmonic detection schemes," IEEE Trans. on Industrial Electronics, vol. 27, no. 2, pp. 718-730, 2012.

[6] Y. Chu, J. Fei, and S. Hou, "Dynamic global PID sliding mode control using RBF neural compensator for three-phase active power filter," Transactions of the Institute of Measurement and Control, vol. 40, no. 12, pp. 3549-3559, 2018.

[7] Y. Chen and J. Fei, "Dynamic sliding mode control of active power filter with integral switching gain," IEEE ACCESS, vol. 7, pp. 21635-21644, 2019.

[8] S. Hou, J. Fei, and C. Chen, "Finite-time adaptive fuzzy-neuralnetwork control of active power filter," IEEE Transactions on Power Electronics, 2019.

[9] J. Fei and T. Wang, "Adaptive fuzzy-neural-network based on rbfnn control for active power filter," International Journal of Machines Learning and Cybernetics, vol. 10, pp. 1139-1150, 2019.

[10] Y. Zhu and J. Fei, "Disturbance observer based fuzzy sliding mode control of pv grid connected inverter," IEEE Access, vol. 6, pp. 21202-21211, 2018.

[11] J. Han and W. Wang, "Nonlinear tracking-differentiator," Journal of Systems Science and Mathematical Sciences, vol. 14, no. 2, pp. 177-183, 1994.

[12] J. Han, "Extended state observer for a class of uncertain plants," Journal of Control and Decision, vol. 10, no. 1, pp. 85-88, 1995.

[13] J. Han, "From PID to ADRC," IEEE Trans. on Industrial Electronics, vol. 56, no. 3, pp. 99-906, 2009.

[14] D. Sun, "Comments on active disturbance rejection control," IEEE Transactions on Industrial Electronics, vol. 54, no. 6, pp. 3428-3429, 2007.
[15] Y. Xia, F. Pu, S. Li, and Y. Gao, "Lateral path tracking control of autonomous land vehicle based on ADRC and differential flatness," IEEE Transactions on Industrial Electronics, vol. 63, no. 5, pp. 3091-3099, 2016.

[16] E. Zhu, J. Pang, N. Sun, H. Gao, Q. Sun, and Z. Chen, “Airship horizontal trajectory tracking control based on active disturbance rejection control," Nonlinear Dynamics, vol. 75, no. 4, pp. 725-734, 2014.

[17] X. Shao and H. Wang, "Active disturbance rejection based trajectory linearization control for hypersonic reentry vehicle with bounded uncertainties," ISA Transactions, vol. 54, pp. 2738, 2015.

[18] T. Jiang, C. Huang, and L. Guo, "Control of uncertain nonlinear systems based on observers and estimators," Automatica, vol. 59, pp. 35-47, 2015.

[19] H. S. Li, Y. Luo, and Y. Q. Chen, "A fractional order proportional and derivative (FOPD) motion controller: tuning rule and experiments," IEEE Transactions on Control Systems Technology, vol. 18, no. 2, pp. 516-520, 2009.

[20] C.-C. Tseng, "Design of fractional order digital FIR differentiators," IEEE Signal Processing Letters, vol. 8, no. 3, pp. 77-79, 2001.

[21] I. N’Doye, H. Voos, and M. Darouach, “Observer-based approach for fractional-order chaotic synchronization and secure communication," IEEE Journal on Emerging and Selected Topics in Circuits and Systems, vol. 3, no. 3, pp. 442-450, 2013.

[22] J. Fei and X. Liang, "Adaptive backstepping fuzzy-neuralnetwork fractional order control of microgyroscope using nonsingular terminal sliding mode controller," Complexity, vol. 2018, Article ID 5246074, 12 pages, 2018.

[23] Y. Fang, J. Fei, and Di. Cao, "Adaptive fuzzy-neural fractionalorder current control of active power filter with finite-time sliding controller," International Journal of Fuzzy System, vol. 10.1007/s40815, pp. 1-11, 2019.

[24] Y. Fang, J. Fei, and Y. Yang, "Adaptive backstepping design of a microgyroscope," Micromachines, vol. 9, no. 7, p. 338, 2018.

[25] J. Fei and Z. Feng, "Adaptive fuzzy super-twisting sliding mode control for microgyroscope," Complexity, vol. 2019, Article ID 6942642, 13 pages, 2019.

[26] J. Fei and H. Ding, "Adaptive sliding mode control of dynamic system using RBF neural network," Nonlinear Dynamics, vol. 70, no. 2, pp. 1563-1573, 2012.

[27] Y. Chu, J. Fei, and S. Hou, "Adaptive global sliding mode control for dynamic systems using double hidden layer recurrent neural network structure," IEEE Transactions on Neural Networks and Learning Systems, 2019.

[28] Y. Huang and J. Han, "Analysis of nonlinear continuous second order extended state observer and design," Chinese Science Bulletin, vol. 45, no. 21, pp. 1938-1944, 2000.

[29] C. Wang, Y. Jin, and Y. Q. Chen, "Auto-tuning of FOPI and $\mathrm{FO}[\mathrm{PI}]$ controller with iso-damping property," in Proceedings of the 48th IEEE Control and Decision Conference. December16-18, , shanghai, pp. 7309-7314, 2009.

[30] A. Oustaloup, J. Sabatier, and P. Lanusse, "From fractional robustness to CRONE control," Fractional Calculus and Applied Analysis, vol. 2, no. 1, pp. 1-30, 1999. 


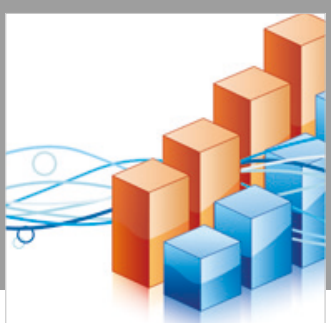

Advances in

Operations Research

\section{-n-m}
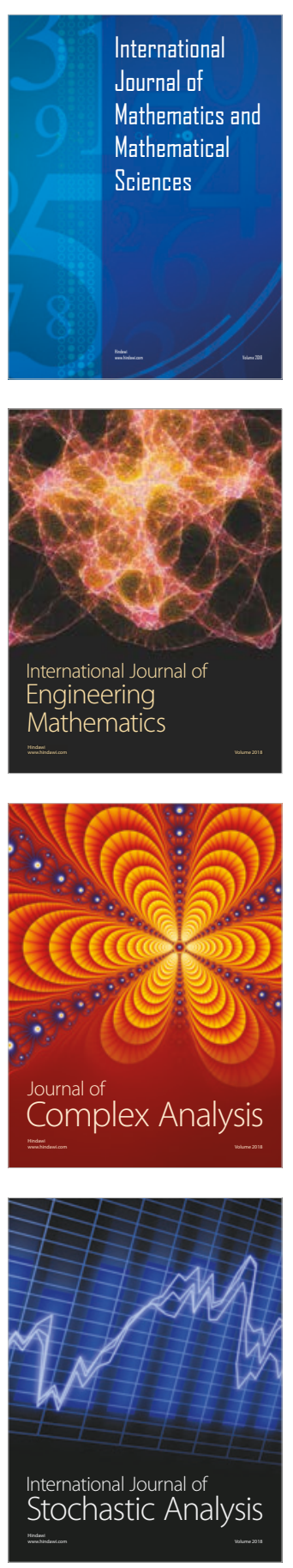
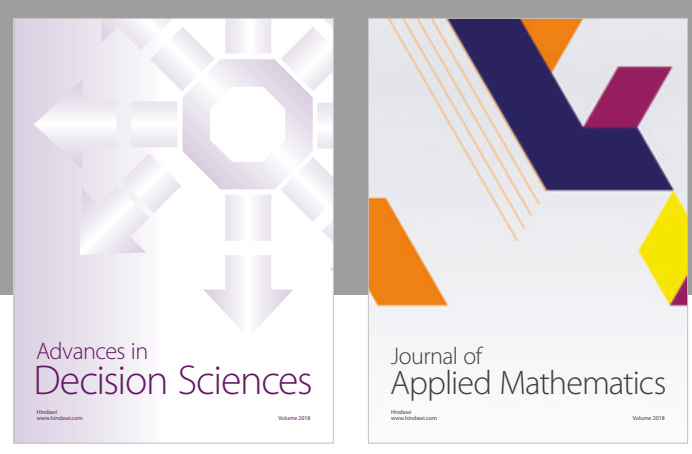

Journal of

Applied Mathematics
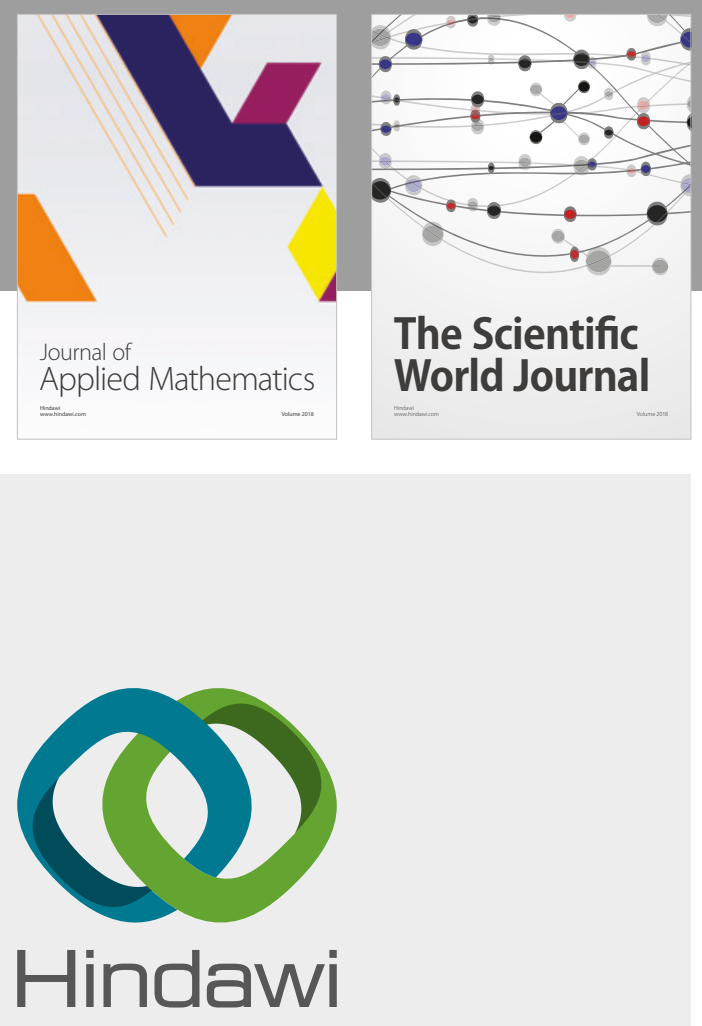

Submit your manuscripts at

www.hindawi.com

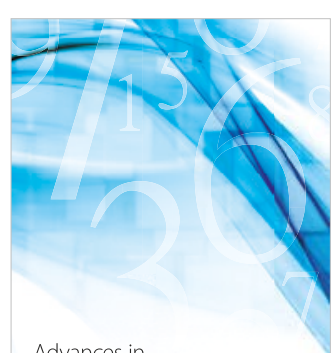

Advances in
Numerical Analysis
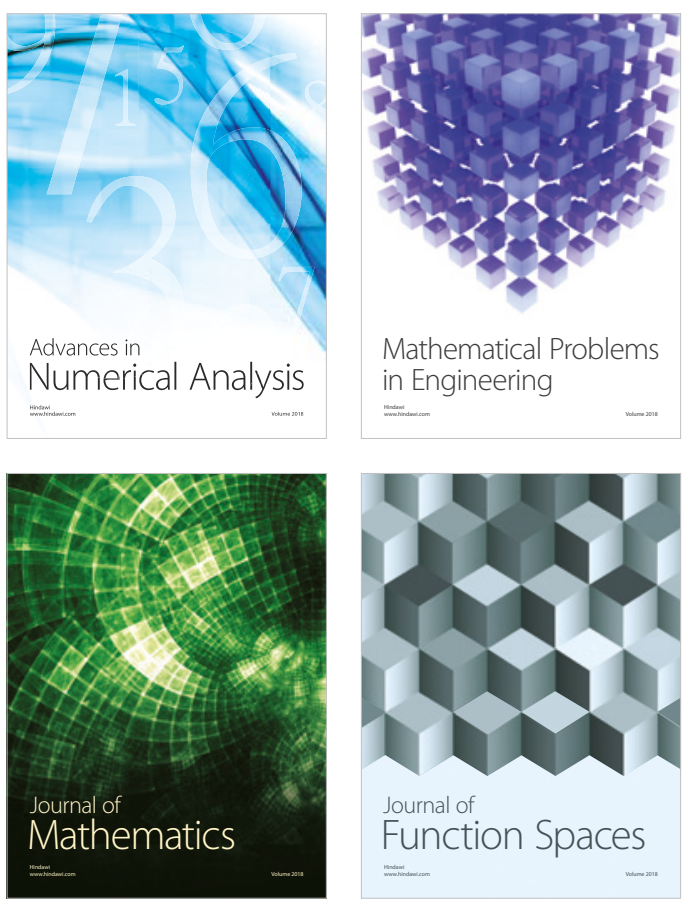

Mathematical Problems in Engineering

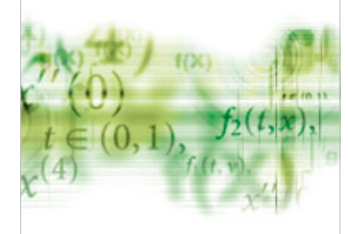

International Journal of

Differential Equations

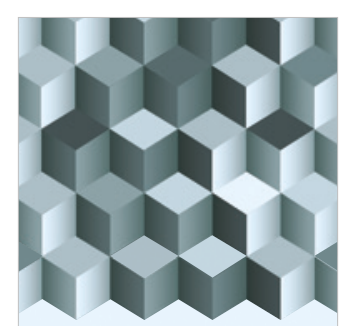

Journal of

Function Spaces
The Scientific

World Journal

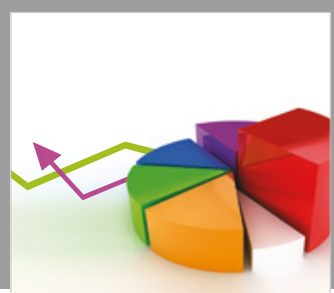

Journal of

Probability and Statistics
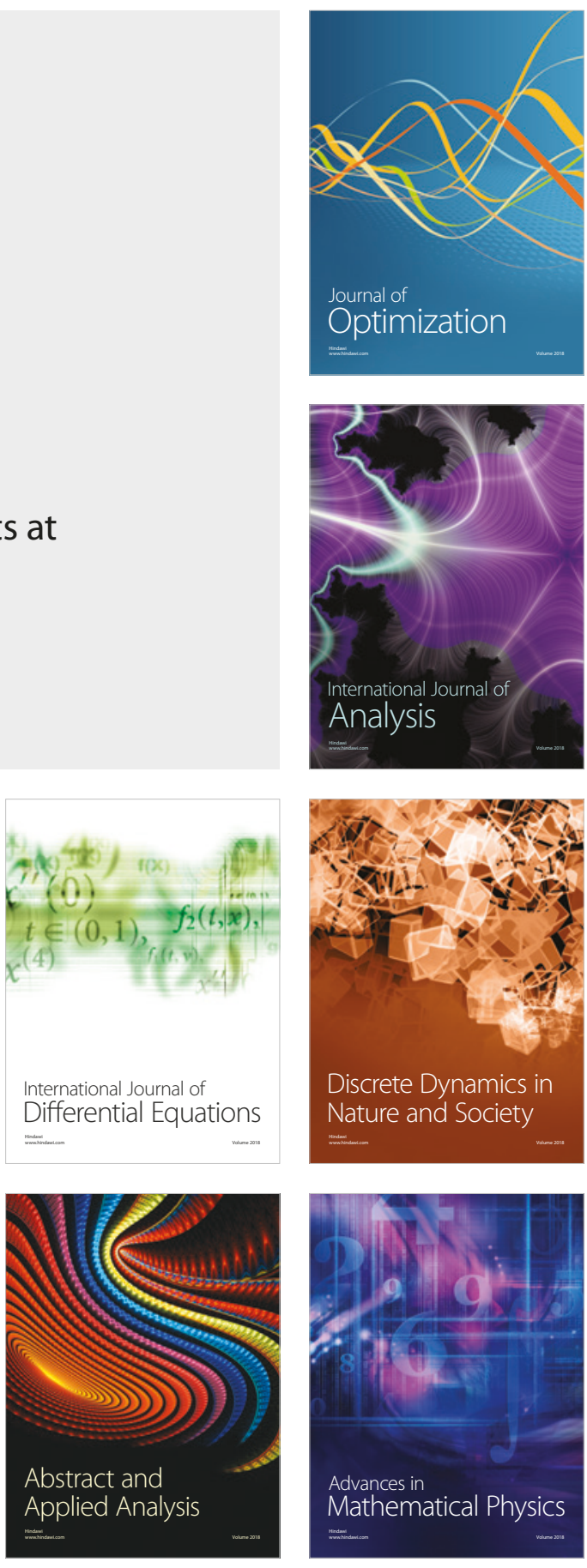